\title{
Teaching during COVID-19: Perceptions of nursing faculty
}

Jolene J. Lynn, Peggy Ward-Smith

Graceland University School of Nursing, Independence, MO, USA

Received: January 14, 2021

Accepted: February 9, 2021

Online Published: February 24, 2021

DOI: $10.5430 /$ jnep.v11n6p43

URL: https://doi.org/10.5430/jnep.v11n6p43

\begin{abstract}
Objective: The COVID-19 pandemic resulted in a significant academic impact for health professions students. As a practice profession, course content in programs of nursing are provided in both web-based or on-line formats and through face-to-face classroom or clinical modalities. In response to social distancing and stay-at-home policies, all course formats became web-based and on-line. This required faculty to transition their course content, assignment, assessment requirements, office hours, and consultations, to an on-line format. Data collected in this qualitative study aimed to describe this experience, from the perspective of undergraduate and graduate nursing faculty teaching in a small, private Midwestern University.

Methods: Study data, guided by semi-structured interviews, were collected using a virtual format from a convenience sample of ten nurse educators. Each interview was performed by the same researcher and analyzed separately, by both researchers using content analyses and qualitative research methods.

Results: Content analyses identified alterations in course structural changes, flexibility in completion of course requirements, providing course content in smaller sections, and being available for academic and psychological support was needed. These data described the personal and professional experiences of faculty specific to course, clinical, and instructor availability.

Conclusions: The necessary adaptations were readily developed and implemented. While the stress and uncertainty associated with change was apparent, clear, pro-active communication resulted in course completion and the ability to maintain the plan of study. Flexibility and adaptability, characteristics inherent in nurses, provided a framework for the necessary changes.
\end{abstract}

Key Words: COVID-19, on-line education, academic programs of nursing, qualitative research

\section{INTRODUCTION}

One consequence of the Corona 19 Virus (COVID-19) pandemic was its impact on academics and health professional students. ${ }^{[1]}$ Students were considered non-essential healthcare personnel, thus dismissed from clinical and practicum rotations. While there were a myriad of reasons for their dismissal, anecdotal data identified the lack of availability of Personal Protective Equipment (PPE) at clinical sites. Triaging PPE was necessary, with the actual provider the preferred candidate. Ideally, health professional students, in clinical settings, function as a member of the healthcare team, but the lack of equipment made this impossible. ${ }^{[1]}$

Healthcare providers are routinely exposed to the risk of infection, heavy workloads, moral issues, fatigue, equipment shortages, and an ever-changing practice environment. ${ }^{[2-4]}$ Adding a COVID-19 pandemic into this scenario, where transmission occurs through multiple portals, and personal consequences include morbidity, increases the risks exponentially. Pfferbaum and North ${ }^{[2]}$ posit that these multiple stressors may result in emotional reactions which exacerbate

*Correspondence: Jolene J. Lynn; Email: jlynn1@graceland.edu; Address: 1401 West Truman Road, Kansas City, MO, USA. 
psychiatric conditions and unhealthy behaviors, such as the misuse or excessive use of alcohol and/or drugs. Provision 5 of the American Nurses Association Code of Ethics ${ }^{[5]}$ for nurses with interpretative statements articulates that "nurses owe the same duties to self as to others, including the responsibility to promote health and safety ...." (e1). Thus, there is a challenge between providing care during the COVID-19 pandemic and maintaining a healthy work force.

Healthcare providers are concerned about leadership, sources of support, and anxiety. Results from a survey study performed by Rajkumar ${ }^{[3]}$ identified impaired sleep, due to anxiety, as the most common complaint of healthcare providers. Data from Shanfelt and associates [4] describes access to PPE, exposure to COVID-19, infecting family members, lack of rapid access testing, uncertainty that organization will care for them if infected, childcare access, support for family as work needs increase, ability to function competently if sent to an unfamiliar area, and lack of access to current information and communication as eight additional sources of anxiety among healthcare professionals.

The initial academic response to the COVID-19 pandemic occurred in March 2020, when institutions providing higher education throughout the United States (U.S.) pivoted courses taught traditionally, or face-to-face, to online formats. To seamlessly make this transition, faculty converted their course modality within several days. This required the development and implementation of all course content, assignments, quizzes, exams, papers, presentations, and projects to be revised. These changes allowed social distancing to be maintained, with virtual, or web-based virtual modalities used as the primary modes of instruction. ${ }^{[1,6]}$ For nursing faculty, this included the necessity of developing clinical simulation activities using web-based formats.

Requirements for teaching in any school or program of nursing includes licensure as a Registered Nurses (RN). Thus, faculty are aware of the complexities associated with the profession. These include long work hours, shifts which include holidays and weekends, providing care to patients with complex healthcare needs, and shortages of appropriate personnel. Inherent personal risks associated with providing care to patients testing positive for COVID-19 along with the persistent shortage of PPE, results in professional and physical stress. This stress, along with the academic changes, impacts nurse faculty along with the academic environment. Consequences of these stressors, as identified by Reyes and colleagues, ${ }^{[7]}$ may include emotional exhaustion, lack of a sense of personal accomplishment, and pressure to maintain a clinical as well as an academic practice. Other examples of stress may be realized through faculty-to-faculty incivil- ity, student incivility, technology, and the complexity of the nurse faculty role. ${ }^{[7]}$ Institutions of higher education have few resources available for faculty, and the urgency of the present scenario renders seeking help difficult. While the prevailing perspective is that serving as a nurse faculty member is 'easier' than clinical practice, the reality is that faculty, to maintain credibility, also serve as clinical experts.

The purpose of this descriptive study was to describe the psychological and physical consequences, specific to nursing faculty, from the COVID-19 pandemic. Study participants included volunteer, consented nurse faculty employed at a private university in the Midwest, whose job requirements included providing required nursing courses in either faceto-face or web-based formats prior to March 2020.

\section{Methods}

Data were collected from a convenience sample of nurse educators, employed by a private university with two Midwestern United States (U.S.) locations. The School of Nursing Campus, located 120 miles south of the flagship campus, has provided undergraduate (BSN) since 1969 and graduate (MSN) nursing education since 1994. Both academic programs have utilized face-to-face and web-based formats for course content since 1987.

Once Institutional Review Board (IRB) approval was secured, a study invitational email was sent to all 18 faculty members of the School of Nursing who met the study inclusion criteria. This email introduced the researchers, explained the study purpose, and provided details regarding how to respond if participation was desired, and the estimated time associated with participation.

Responses were received from 12 individuals; one failed to meet study inclusion criteria and one did not complete the required interview. Thus, there were 10 participants who completed all study activities. This represents a $66 \%$ study enrollment rate, and a 55\% study participation rate. Each web-based interview was conducted by one of the researchers (JJL), at a time convenient for the participant, and digital audio-recorded within the web-based format. Verbal consent was secured prior to each interview; each participant was asked to provide some demographic data, and data collection commenced. Participants were referred to by their study number, which provided confidentiality to these data and the inability to link any data set to a specific participant.

Guided by qualitative research methods, ${ }^{[8]}$ the global research question "How has COVID-19 impacted your teaching" initiated the interviews. Four additional semi-structured questions were used to ensure a complete description. These questions were (1) how has your teaching been altered in 
response to the necessary changes COVID-19 required, (2) what physical and/or psychological changes have you noticed in your students since the course format was altered, (3) as a faculty and a nurse, please describe how you perceive your role in assisting students to remain on track to complete the course requirements, and (4) what interventions do you believe your students would like you to provide. Once responses were received from the research questions, each participant was asked if there was anything they would like to add. Once all data were collected, study participation was complete, and the digital audio-recording was turned off and placed in a password protected file on the researcher's computer.

Once all interviews were completed, the data file was electronically shared with the second researcher (PWS) for analyses. Each researcher transcribed the digital audio-recordings, then the transcriptions were compared to the audio-recording and checked for accuracy. Once all data were transcribed, analyses were guided by the seven steps outlined in Colaizzi's ${ }^{[8]}$ phenomenological analyses technique. These steps include (1) reading all data to obtain a feel for them, (2) reviewing each interview and identifying significant statements, (3) identify the meaning of each significant statement, (4) organizing these meanings into clusters of themes, then compare the themes to the original interview data for validation, while noting discrepancies, (5) develop a complete description of the experience, (6) summarize the description into statements, and (7) request that the participants read these statements, as a measure of validity. Once the significant statements were validated by the participants, Patton' ${ }^{[9]}$ qualitative content analyses techniques were used to reduce these data into core consistencies and meanings. Thus, theme identification and exemplars for each interview question were guided by qualitative research analyses methods, with consensus used to label each theme. Once data were analyzed, the electronic file on the personal computer of the second researcher (PWS) was deleted. Research data maintained on the computer of the primary researcher (JJL) will be deleted in compliance with regulations and policy of the IRB approver.

\section{Results}

Demographically, these participants were primarily female (90\%), between the ages of 30 and 69 years, with a mean of 40.8 years. Years as a registered nurse (RN) ranged from 8 to 47 years, with a mean of 20.3 years, while years as a faculty member at the study site ranged from 1 to 20 years, with a mean of 8.7 years. Data collection time ranged from 7 minutes 21 seconds to 19 minutes 59 seconds, with a mean of 11 minutes 10 seconds.

Published by Sciedu Press
Member checks, used to validate and provide rigor in qualitative research, as described by Coliazzi,${ }^{[8]}$ were secured from available participants prior to formatting responses to each study research question. This was done to provide validity and trustworthiness to these data. The participants that reviewed these results agreed that they reflect their experiences.

\subsection{Global research question}

Responses to the global research question, describing how COVID-19 impacted teaching, evolved into two categories, based on the academic program (undergraduate and graduate). Faculty in the undergraduate program provided face-toface, online, and clinical learning experiences. These participants were required to alter their content delivery method to online, restructure laboratory enrollment to provide social distancing, and develop alternate methods to provide simulated clinical experiences. Social engagement and active learning experiences were reformatted in an effort to retain some personal contact. Participants in the graduate program, which utilizes a web-based format for course content, altered the clinical experiences which ceased due to the inability to access health care settings. As noted by participant \#4, who provides undergraduate education, "nursing, is an applied profession, and we provide care which implies touch. COVID-19 required teaching, in any academic program, to switch from $100 \%$ hands-on to $100 \%$ hands off."

\subsection{Theme \#1: How your teaching was altered in re- sponse to COVID-19?}

Alterations in teaching, in response to COVID-19 limitations, did not vary by academic program. Each participant expressed the desire to not alter course content or course requirements in response to the changes. Teaching alterations included (1) changing face-to-face lectures to a web-based format, (2) providing course content online, through video, and (3) altering and developing simulated clinical experiences.

Lectures provided in a face-to-face format prior to COVID19 , continued to be held during the scheduled class time. The decision to tape these varied with one participant describing

"my teaching is not as good without the personal contact, and watching a video is passive. I do not tape my lectures, and I do not tape the question and answer sessions I have after every test (participant \#5).”

Another participant (\#3) altered her lectures by

"instructing students to post their questions in the chat box during the lecture. I then respond 
to these after content is provided. That prevents disrupting the lecture."

Course materials, when provided online prior to COVID19 , required little, if any, alterations. Course content was amended and described by participant \#2 as

"providing the content in smaller chunks, rather than a one-hour lecture." This, in the perception of this participant, "allows the student to watch something when they have time and providing the content in 15-20 minute blocks of time seems to decrease their stress."

Clinical placements, vital for both undergraduate and graduate nursing education, have been decimated by COVID-19. Students are not essential workers, rendering them unable to be present in many healthcare settings. This has challenged nursing faculty, and, as noted by participant \#8

"How much clinical experience can a student miss and still become a safe provider?"

The use of simulation, telehealth, role playing, and videos have been implemented in an effort to provide learning experiences. Yet, as noted by participant \#9,

"connectivity has been lost. The ability to perform a clinical assessment, in a no-contact environment, is impossible - content may be grasped, but the ability to apply that knowledge cannot be assessed in this environment."

Another participant (\#1) expressed the notion that

"when people are dying, despite all the care being provided, it is hard to focus on an ear assessment. I mean, really, everything seems inconsequential when you have the mortality rates we have."

Other academic changes made in response to COVID-19, as described by these participants, include

"I was unable to fail a student on a virtual exam ... there were too many concerns. Thus, we have paused that policy and the person remains in the program. I may not agree with this solution, but it seems justifiable."

3.3 Theme \#2: What physical and/or psychological changes did you noticed in your students since the course format was altered?

Physical and psychological changes, since the onset of COVID-19 academic alterations, were similar in both undergraduate and graduate students. Physical changes were noted by participant \#4 to be difficult to assess, beyond looking tired. Psychological changes described by students to these participants included anxiety, stress, depression, fatigue, decreased concentration, decreased ability to cope, frustration, crabby, distracted, and irritability. Participant \#10 best describes this as

"Nursing school is stressful, all the things that changed in response to COVID-19 both added to the causes of stress and enhanced the stressors already present."

Participant \#3 also remarked on the 'routine' level of stress associated with being a nursing student. However, this participant also described

"every human being has encountered additional stress and additional stressors in response to this global pandemic. My approach with the students has been to recognize this, respect that everyone ... me included ... are navigating new territory, and to have grace, patience, and be forgiving."

Stressors, for the older student, or adult learner, were identified by participant \#4. These were described as

"beyond COVID-19 and their academic changes, the non-traditional student also may have child care issues if their kids are not able to go to school, they may have loss of job, or decreased work opportunity issues for their significant other, money, having a quiet space at home to complete their school work, constant distractions, if they are employed as a nurse there may be required overtime ... the consequences of COVID-19 are far-reaching."

\subsection{Theme \#3: In your role as faculty and nurse, what interventions did you develop and implement that as- sisted students to remain on track to complete the course requirements?}

Each participant provided several examples of how they are assisting students so that they can remain in school, and ontrack for course completion. The examples provided were similar regardless of educational track. Participants identified proactive interventions, such as frequent communication, both to the class in general, and to students that appear to be struggling specifically. Contacting students when test scores drop, or when assignments are late, was perceived as a preventative measure to provide support and to provide flexibility in completing course assignments. Students were encouraged to contact their instructor if circumstances were 
changing and accommodations were negotiated. Participant \#10 described this as

"I tell my students that I am willing to work with them, but I cannot help you if I do not know. I am obligated to follow the policies, unless there is an extension provided."

Clarifying policy changes that were occurring in clinical as soon as possible was intended to decrease stress, make students aware that faculty were working on alternate arrangements, and to validate the experience as challenging. While creativity and flexibility were identified as critical components, allowing students to suggest options kept them engaged in their education. Participant \#1 described their faculty role as

“ ... trying to be a role model. Yes, I am upset and frustrated - probably more that the students are - but maintaining an aura of calm, while allowing them to rant, got things off the table. Then we moved on."

Alterations in course assignments, due dates, testing methods, and presentations for all courses were necessary. While each participant described their personal flexibility, which were guided by course requirements and student need, participant \#5 summed this experience as

"in the end, I do not believe that many students needed extensions, or adaptations, to meet the course requirement, but they needed to know that the option was available."

The overwhelming perception was that, while course delivery and expectations were flexible, course requirements were not. The concern that limited clinical experience, both in terms of time and complexity, would impact expertise upon graduation was expressed by participant \#7. "The clinical rotations, for nursing students, should provide them with exposure to health situations that are difficult. It is the only way that they will be 'boots on the ground ready' when they graduate. We are not able to do that - our clinical sites are not able to allow students to be present in these situations. My teaching is not as rigorous. I can be supportive, but I am concerned, and not really happy."

Students offered suggestions to faculty members aimed at allowing them to complete their course. Participant \#4 explained that

"several of my students had ideas for clinical opportunities. Providing clinical hours during the night shift was possible. The hospital could still maintain their personnel policies, and the pace was slower, which actually allowed increased learning opportunities."

One benefit of a course lecture being provided virtually was "the ability to attend class despite having a COVID-19 test being positive" (participant \#3).

Participant \#9 did comment that the questions asked about physical changes for students, but not about physical changes for faculty.

"I can't help but think there is other faculty out there, I have rheumatoid arthritis, you get that gel, you get stiffened up, I have to make myself walk around, so trying to find a place where I can sit more comfortably, so that's unique more to me. It's much easier for me to be in the classroom and walking around".

\subsection{Theme \#4: Descriptions of interventions believed to be wanted, as requested by your students}

The consensus specific to what students would like the faculty to do mirrored what faculty are providing. Students have asked for clarity and the ability to contact their instructor beyond office hours or to discuss something not specifically school or course related. Students have requested post-test review opportunities, where they can discuss their missed answers, and use this as learning opportunities. Prior to COVID-19, this was done in a face-to-face format. Altering the format to virtual was perceived by students as exposing them to others knowing their deficits. Thus, a 'frequently missed test question' discussion board was developed by the instructor. Content within this discussion board focused on the top 10 missed test questions, which was supplemented by the opportunity to discuss additional concerns using the private office forum. The broader view here was that

"students are isolated. If they are not working, they are primarily home-bound, and have limited human contact. We need to be aware of that" (participant \#2).

When queried about what students would like faculty to provide, participant \#1 feared that asking that question to students would result in

"they would like us to provide the answers to the tests, or simply not have the test itself. They would like us to delete the required assignments, spoon feed them the content, and award them all A's. Yet ... most of my students really want to be nurses, and know, on some level, that life does not work that way. I am trying to use this 
public health disaster as an opportunity to teach them flexibility, resilience, and persistence. It may not work, and it is my personal quest, but what students 'want' and what students 'need' are two different concepts."

\section{Discussion}

The findings from this study indicate that the COVID-19 pandemic has impacted education for both nursing faculty and nursing students. Teaching methods, schedules, opportunities, and personal contact were all altered to allow students to maintain their academic status. From the teaching perspective, an increased use of technology was used to provide course content, simulated and web-based modalities, including telehealth, were used to provide clinical hours, and flexibility in course assignment due-dates and testing opportunities broadened the opportunities to learn, despite the social distancing obstacles. Faculty were required to pivot their teaching, both didactic and clinical, so education could continue, seamlessly. Despite the challenges, most embraced the opportunity. Several stating that the interventions mentioned (extensions, flexibility) were things they routinely provided but restated them and were proactive in assuring students were aware of the opportunities. Students, in the perspective of these faculty members, seemed to initially struggle, yet this seemed to dissipate over the course of the semester, and change was "part of things" during the summer term. Communication with candor, coupled with patience and flexibility among faculty and students allowed courses to continue, assignments to be completed, and course grades to be awarded without delay.

Prior to the COVID 19 Virus pandemic, the World Health Organization (WHO) ${ }^{[11]}$ declared 2020 as the year of the nurse and midwife. This campaign aimed to recognize the critical contributions nurses make to global health. Then, the pandemic struck, which altered society, and healthcare, in unimaginable ways. While providing care to patients during this pandemic has been challenging, the entryway to a nursing profession begins with an academic experience. Thus, nursing faculty are charged with teaching the skills, competencies, decision making and critical thinking capabilities as well as demonstrating the persistence and resilience necessary to succeed as a nurse. The participants in this study describe the steps they undertook to assure that the academic experience of student nurses continued unencumbered by the pandemic. Psychological interventions, such as asking for course accommodations, asking for clarity, and creatively meeting course objectives are skills that will transfer once the student has graduated. The COVID 19 Virus has demonstrated the importance of nurses, and the critical nature of their education.

\section{Conclusion}

Being a nurse has always required both planning and flexibility. The ability to adapt, readily and quickly, to changing scenarios allows nurses to provide timely and appropriate care, while limiting personal stress. While COVID-19 has upended the personal, academic, and professional lives in so many ways, much of this reflects healthcare, and nurses' response to change. The circumstances provided faculty with the opportunity to model coping, adapting, and adjusting behaviors. The provision of healthcare needs team members that are adaptable and flexible, and always have a "plan B". The results of this study describe how nursing faculty members adapted to, and provided interventions for students, aimed at circumventing COVID-19 related challenges. While results from qualitative research are not meant to generalized, transferability as defined by Lincoln and Guba, ${ }^{[10]}$ is the ability of research findings to be transferred to other settings. Discussions between the researchers during data analyses revealed that the interview content to support their experiences were comments heard during the transition process. Thus, transferability to other academic settings which provide healthcare professional degrees may be warranted. The inclusion of member checks after the analyses strengthened the trustworthiness of these results.

\section{CONFlicts of Interest Disclosure}

The authors declare that there is no conflict of interest.

\section{REFERENCES}

[1] Rose S. Medical student education in the time of COVID-19. JAMA. 2020; 323(21): 2131-2132. PMid:32232420 https ://doi .org/10 $.1001 /$ jama. 2020.5227

[2] Pfefferbaum B, North CS. Mental health and the COVID-19 pandemic. NEJM. 2020; 383; 6. PMid:32283003 https ://doi .org/ 10.1056/NEJMp2008017

[3] Rajkumar RP. COVID-19 and mental health: a review of the existing literature. Asian Journal of Psychiatry. 2020; 102066. PMid:32302935 https://doi.org/10.1016/j.ajp.2020.102 066

[4] Shanafelt T, Ripp J, Trockel M. Understanding and Addressing Sources of Anxiety Among Health Care Professionals During the COVID-19 Pandemic. JAMA. 2020; 323(21): 2133-2134. PMid:32259193 https://doi.org/10.1001/jama.2020.5893

[5] American Nurses Association. Code of Ethics for Nurses. Silver 
Springs, MA; 2019.

[6] Chick RC, Clifton GT, Peace KM, et al. Using technology to maintain the education of residents during the COVID-19 pandemic. Journal of Surgical Education. 2020; 77(4): 729-732. PMid:32253133 https://doi.org/10.1016/j.jsurg. 2020.03.018

[7] Reyes AT, Andrusyszyn A, Iwasiw C, et al., Nursing students' understanding and enactment of resilience: a grounded theory study. JAN. 2015; 71(11): 2622-2633. PMid:26193950 https ://doi .org/10 $.1111 / j$ jan. 12730
[8] Colaizzi PF. Reflections and research in psychology. Dubuque, IA: Kandall/Hunt; 1978.

[9] Patton MQ. Qualitative research and evaluation methods. Thousand Oaks, CA: Sage Publications; 2002.

[10] Lincoln MQ, Guba EG. Naturalistic inquiry. New York: Newbury; 1985.

[11] World Health Organization (WHO). 2020 - Year of the nurse and the midwife. Available from: https://www. who.int/campaign s/year-of-the-nurse-and-the-midwife-2020 